\title{
Research on Key Technologies of New Energy Grid-Connected Power Generation System
}

\author{
Yuanyuan Liu' ${ }^{1,2}$, Anping Bao ${ }^{1}$ \\ ${ }^{1}$ Nanjing College of Information Technology, Nanjing, China \\ ${ }^{2}$ CQC-Trusted Testing Technology Co., LTD, Nanjing, China
}

Keywords: new energy; grid-connected power generation; power generation system; key technologies

\begin{abstract}
With the rapid development of micro-energy power generation technologies, distributed power generation technologies, and energy storage technologies represented by new energy and renewable energy, new energy and grid-connected power generation is gradually becoming a research hotspot. Firstly, the main new energy distributed generation technology is introduced, and then the related concepts and basic structure of the micro-grid is given, and the key technologies in the new energy grid-connected power generation system are described. Finally, the development trend of the new energy grid-connected power generation system is the distributed hybrid energy system and the intelligent micro-grid under the framework of the strong smart grid.
\end{abstract}

\section{Introduction}

Since the third industrial revolution, human society has achieved unprecedented development in economy and science and technology, accompanied by a series of problems such as the massive consumption of conventional fossil energy and the environmental pollution and resource shortage caused by it, forcing humans to have to Start looking for clean, renewable energy, which is new energy. Compared with traditional coal, oil, natural gas and other fossil energy sources, new energy generally has the characteristics of less pollution and large reserves, which is of great significance for solving the increasingly serious environmental pollution and resource scarcity in the world today [1]. The pressures on resources and the environment have also brought new challenges to the power system. The use of new energy to gradually replace traditional energy sources for power generation will be the trend of power industry development in the future. It can be seen that new energy power generation has a good development prospect and practical value.

\section{Types of New Energy Power Generation and its Principle Characteristics}

New energy power generation mainly includes solar power generation, wind power generation, biomass power generation, geothermal power generation, tidal power generation and so on, as Fig.1.

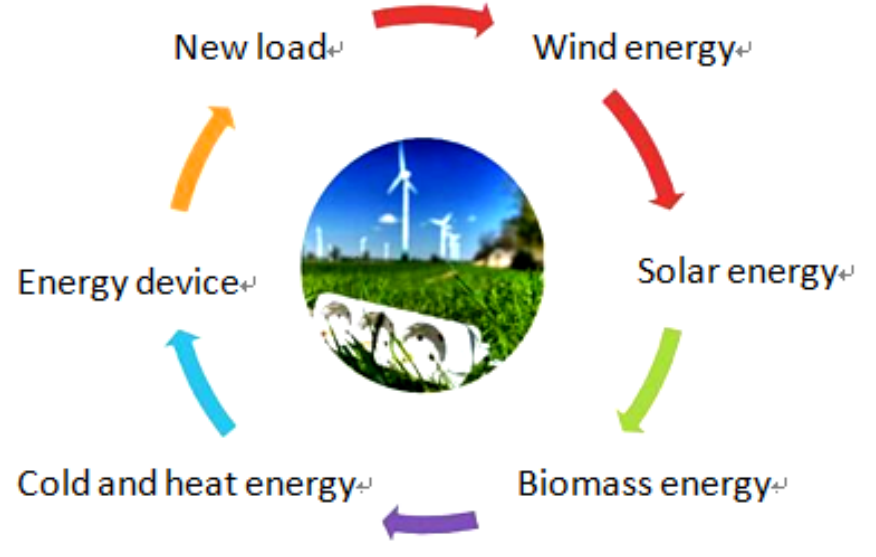

Fig. 1 Types of new energy generation 


\subsection{Solar energy generation}

Solar energy refers to the energy generated by the continuous nuclear fusion reaction process inside the sun. It is a huge energy source. It is estimated that the annual solar radiation energy received by China's land area is equivalent to 2.4 trillion tons of coal [2]. Solar power generation is also called photovoltaic power generation. Its basic principle is to use the photovoltaic effect to produce electromotive force through light, and then output electrical energy to achieve photoelectric conversion. Simply put, solar power is the direct conversion of sunlight into electricity through solar cells. A solar cell is a flat crystal made from a variety of thin films of semiconducting materials with different electronic properties that can generate a strong internal electric field [2]. Monocrystalline silicon cells, polycrystalline silicon cells, and amorphous silicon cells are three types.

\subsection{Wind power}

Wind power is the conversion of wind energy into mechanical energy, and then converted into electrical energy. The basic principle is that wind is used to blow the wind wheel and the rotation of the generator rotor is driven by the mechanical rotation of the wind wheel to generate electrical energy. Wind energy is a clean renewable energy source. Compared with conventional power generation, wind power generation has the advantages of sufficient energy, no fuel consumption, no environmental pollution, small footprint, short construction period, and mature power generation technology [2]. Among the new energy development technologies in the world today, wind power generation is the most mature and most commercially valuable power generation method. Its installed capacity is continuously expanding, and the proportion of global wind power generation to total power generation is gradually increasing.

\subsection{Biomass power generation}

Biomass energy is a kind of energy form that the green plants store in the biomass through the photosynthesis, converts the solar energy into chemical energy, and is a kind of resource with abundant resources and no pollution [2]. Biomass power generation includes agricultural and forestry waste combustion power generation, biomass gas power generation, urban waste incineration power generation, and biogas power generation. Biomass power generation has the advantages of good power quality, high reliability, and high economic value.

\subsection{Geothermal power}

There is a huge amount of thermal energy inside the earth. Geothermal energy is the energy released from Earth's internal heat to the earth's surface. Geothermal power is the transformation of geothermal energy into mechanical energy, which turns mechanical energy into electrical energy. It uses underground hot water and steam as its power source. A new type of power generation technology, the principle of which is basically the same as thermal power generation, that is, the heat energy of steam is converted into mechanical energy through a steam turbine, and then the generator is driven to generate electricity [3].

\subsection{Tidal power}

Tidal energy is the energy contained in the tide. It is also an inexhaustible new energy source. Tidal power generation is the use of seawater fluctuations and the resulting water level difference to drive the turbine and the turbine drives the generator to generate electricity. The principle is not much different from the general hydroelectric power generation [3]. In other words, dams are constructed in bays or in estuaries with tides to form reservoirs, and power generation is carried out by using the water level difference between the inside and outside of the dam and the ebb tide. Tidal power generation is affected by the cyclic changes in tides and is intermittent.

\section{New Energy Generation Grid-connected Technology}

In recent years, research on photovoltaic, wind power, and fuel cell distributed generation systems has been deepened at home and abroad, and many technical issues have been proposed and discussed. 
Key technical issues include (but are not limited to) power system architecture, key components, and micro-network technology operations control, energy management and fault detection and protection technologies.

The structure of new energy power generation system uses a distributed power generation system composed of multiple energy sources in parallel. In the small-scale distributed generation system, there is a combination of multiple energy sources such as wind energy, solar energy, fuel cells, micro-turbine, and energy storage systems [3]. Most of them need to connect to the micro-public power grid in the form of a parallel connection of inverters. Power system structure of new energy grid-connected is shown as Fig.2.

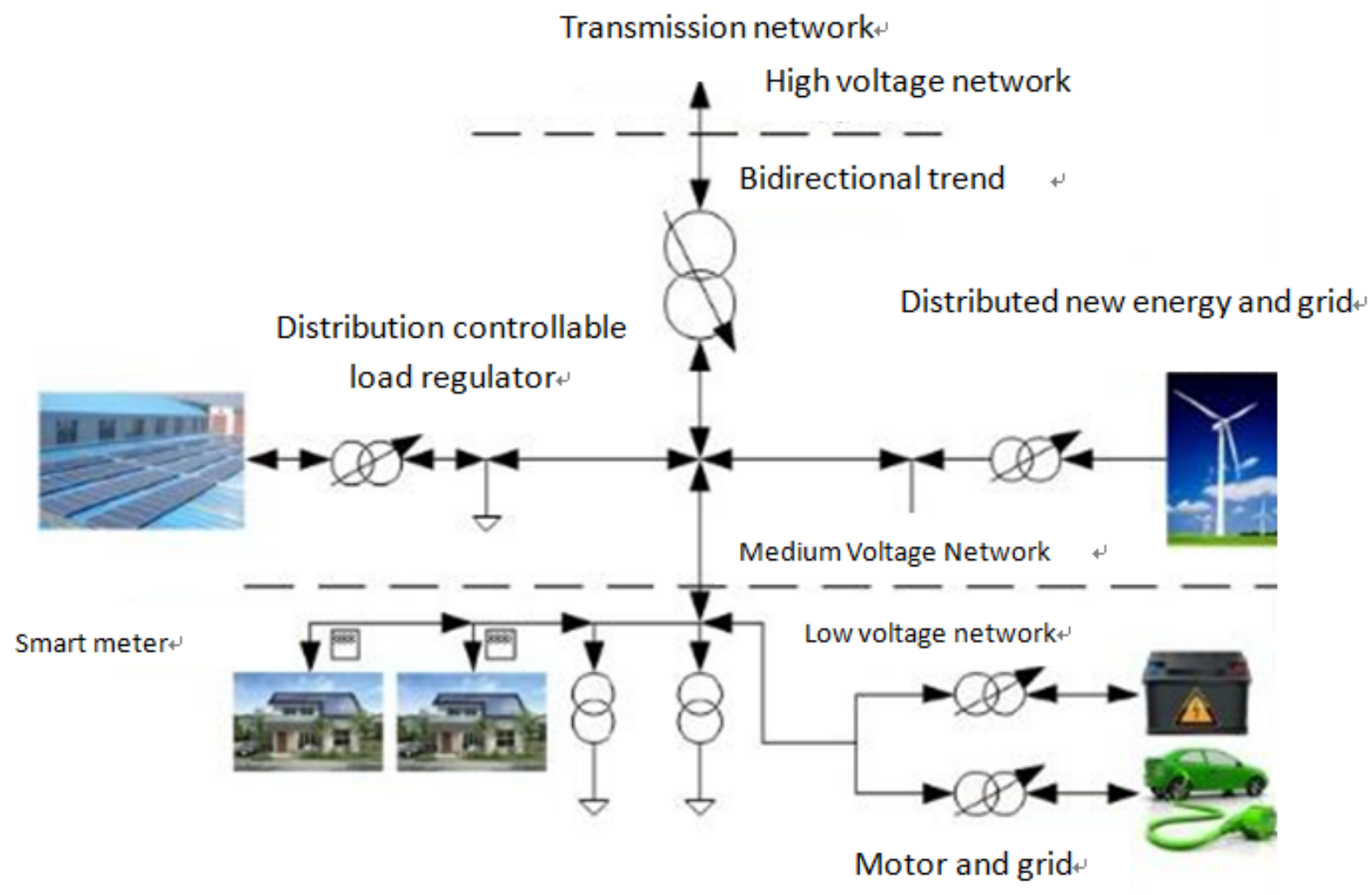

Fig. 2 Power system structure of new energy grid-connected

\subsection{Key components of power electronics technology}

Power electronics technology is one of the key technologies for the development of various types of renewable energy and the development of distributed generation. According to the special needs of the microgrid, it is necessary to develop some new power electronic devices based on power electronics technology, such as grid-connected inverters, static switches, and power quality control devices [4]. In new energy grid-connected power generation systems, grid-connected converters, static switches, and power quality control devices are key components that have a major impact on the operation of the system.

1) Grid-connected inverter. Photovoltaic cells, fans, fuel cells, and energy storage components all need to be connected to the micro-grid system network through power electronic converters. These converters may include both rectifiers and inverters, or they may only be one inverter. The converter has the characteristics of fast response, low inertia, and weak over current capability. At the same time, the inverter applicable to the microgrid needs to have the functions of a conventional inverter and be able to operate in parallel, but also needs some control functions according to the special requirements of the microgrid system, such as active-frequency droop control function and voltage [4]. Therefore, the topology and operation control of the inverter become the key technologies in the micro-grid.

2) Static switch. The static switch is placed at the common connection point between the connected micro-network and the main network. In the event of major network failures, power 
quality, etc., the static switch should automatically switch the micro-grid to the islanding state: thereafter, when the above event disappears, it should also automatically reconnect the micro-grid to the main network.

3) Power quality control device. Any access to the DER unit will have a more or less influence on the power quality in the system. If they are not controlled properly, they will negatively affect the voltage waveform, frequency and power factor, especially the random energy such as solar energy and wind power. The frequent start-stop operation and power output change may bring power quality problems to the users of the connected system. The existence of a large number of single-phase distributed power supplies in the microgrid also increases the three-phase imbalance of the power distribution system. Level; and the electronic load is susceptible to transients, drops, harmonics, momentary interruptions, and other disturbances, all of which require attention. In summary, there are many unique issues related to power quality in microgrid and distributed power microgrid power distribution systems. The integrated monitoring technology of power quality is one of the key technical issues for ensuring the safe and reliable operation of the microgrid.

\subsection{Key technologies for photovoltaic power grid integration}

Photovoltaic power grid-connected systems mainly include solar arrays and grid-connected inverters, supplemented by corresponding centralized control systems. Operating in a microgrid, accessing an interconnected or ultra-high voltage grid through a low- and medium-voltage distribution network is an important feature of grid-connected photovoltaic systems. The basic requirement for the grid-connected PV system is that the frequency and phase of the sine wave current output by the inverter is the same as the frequency and phase of the grid voltage [5]. In order to meet this condition, the key to grid-connected photovoltaic power generation technology lies in grid-connected inverters. Improvements in inverter performance are critical to improving the efficiency and reliability of the system, increasing the lifespan of the system, and reducing costs.

With the continuous improvement of power electronics, microelectronics, and modern control theory, inverter technology is developing in the direction of higher frequency, higher power, higher efficiency, and smaller volume. Current research on inverters focuses on passive and active protection detection methods for "islanding effects," and issues such as MPPT control, grid current control, and voltage amplification.

\subsection{Wind power grid-connected key technologies}

For wind farms, when the wind is not enough to remove the wind turbine from the system, to supply power to the load at the wind farm, the system will transmit active power to the wind farm to a limited degree. At this time, reactive power compensation may be required to ensure stable operation of the system. Conventional DC does not have the ability to send reactive power, and it still requires a large amount of reactive power compensation devices, which also increases the area of converter stations, and is therefore not suitable for use in wind farms [5].

At present, the use of AC grid connection is the choice of the vast majority of wind farms. However, there are currently some technical bottlenecks in wind farms through AC grid connection: Firstly, the use of AC grid connection requires that the wind farm and the connected AC system must keep frequency synchronization strictly, and the fan is more sensitive to AC bus voltage fluctuations at the grid connection. Existing operating experience shows that the voltage fluctuation of the AC system is one of the main reasons for the fan to exit the network. Secondly, in the event of a fault in the AC system, the stable operation of wind farms often requires the installation of reactive power compensation devices at the outgoing end of the bus to improve the fault-tolerant capability of the wind farm. However, as a result, the investment in wind farms has been increased. In addition, the compensation device may adversely affect the maximum wind energy capture of the fan and the fan controller itself.

\subsection{Key technologies for geothermal power generation}

Geothermal power generation The turbine generator used in the power generation system generally uses a synchronous generator, and the synchronous generator is put into the grid for parallel 
operation (grid operation) [6]. Several conditions must be met: 1) The voltage of the generator should be equal to the grid voltage and the same phase; 2) The frequency of the generator should be the same as the grid frequency; 3) The phase sequence of the generator should be consistent with the phase sequence of the grid. However, the first two conditions are allowed to be slightly different, and the third condition must be absolutely satisfied because when the generator is connected to the grid, the voltage difference and phase difference between the same phase in the objective are unavoidable, and the generator is not connected to the grid itself.

\subsection{Micro-net technology}

Combining various types of micro-energy with energy storage devices and power electronic devices organically, it is constructed as a microgrid consisting of a power generating equipment and energy storage equipment, and "flexible" networking with large power grids is realized through power electronic devices. Micro-grid technology partially solves the problem of large-scale grid-connected operation of distributed power supplies [6].

1) Coordinated control issues among multiple micro power supplies in a microgrid. In a microgrid system, there are pluralities of micro power supplies, which may be micro power supplies of the same type, or micro power supplies of different types. The external characteristics, time constants, and components of these power supplies are different from each other, and the power system The energy is balanced. Such as: a variety of micro-power supply steady-state, transient, dynamic analysis model, the stability of multiple converters and their coordination and control issues.

2) Micro-grid fault detection and protection technology. The introduction of the DER unit makes the protection and control of the micro-grid system different from the protection and control in the conventional power system in terms of fault detection methods and protection principles, such as in addition to over-voltage and under-voltage protection. In addition, special protection functions for anti-islanding and low-frequency protection are also included for distributed power supplies. In addition, the conventional protection control strategy is for the protection of a unidirectional power flow system, and the flow may flow in two directions in the micro-grid system, and the fault current level will be very different with the system structure and the number of connected DG units. Traditional relay protection devices may no longer play the necessary protective role, and may even cause damage to these protection devices. Therefore, it is necessary to develop a fault detection and protection control system that can operate completely different from conventional protection modes.

\section{Summary}

In today's society with diversified product packaging types and diversified design methods, product packaging interaction design with user experience has become the mainstream trend of product packaging design in the current era, and it also plays a role in further satisfying users' emotional experience, product packaging experience, and meeting user needs. In short, based on the user experience, product packaging interaction design, with the continuous development of interactive technology, it should improve the user's understanding, emphasis on the user experience, based on user needs, and constantly optimize product packaging interaction design, bring people Brand new product packaging experience.

\section{Acknowledgement}

Scientific and Technological Innovation team of Jiangsu Province Qing Lan Project (Code Z150107).

\section{References}

[1] X.Y. Zhao, New energy development outlook, Electric Power Technology, 2009, vol.10, pp.7-14.

[2] Y.M. Qian, The development of new energy and renewable energy power generation technology, Journal of Xihua University, 2007, vol.1, pp. 50-52. 
[3] X.Y. Li, Research on power system with distributed generation devices, Automation of Power Systems, 2005, vol.24, pp.90-97.

[4] Y.B. Sheng, New energy large-scale application and renewable energy grid-connected power generation, Journal of North China Electric Power University, 2009, vol.1, pp.10-14.

[5] Ch.Sh. Wang, Energy renewable and generation distributed access technologies, China Southern Power Grid Technology, 2008, vol.6, pp.1-6.

[6] Y.G. Zhang, Key technologies in Microgrid research, Power Grid Technology, 2009, vol.11, pp. 6-l1. 